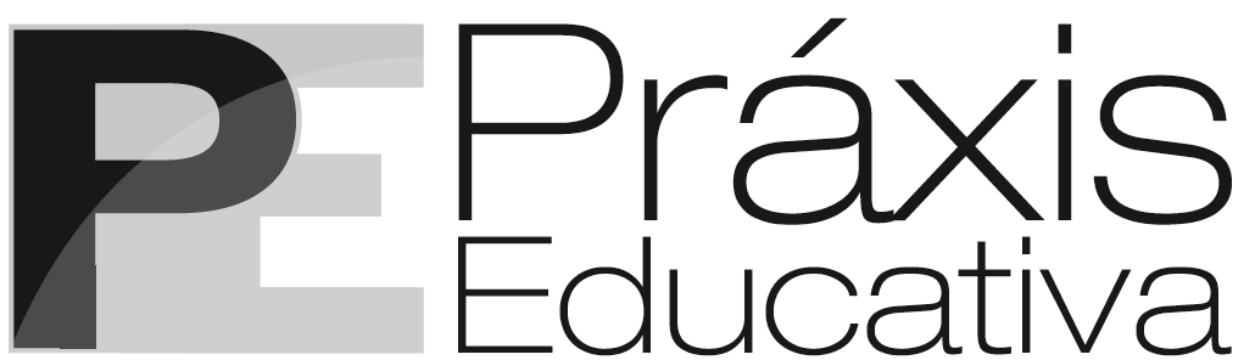

ISSN 1809-4309 (Versão online)

DOI: 10.5212/PraxEduc.v.12i2.0013

\title{
Sobre o compromisso da Educação Física escolar com a inclusão social dos negros
}

\section{On the commitment of school Physical Education with social inclusion of the black students}

\section{Acerca del compromiso de la Educación Física para la inclusión social de los negros}

\author{
Vanessa Gomes de Castro*
}

\begin{abstract}
Resumo: Trata-se de uma problematização acerca da demanda histórica da população negra por inclusão social, bem como o compromisso da Educação Física escolar com essa demanda. Como pano de fundo, de um lado, está a exclusão dos negros na sociedade brasileira, decorrente do regime escravocrata, assim como sua luta para reverter esse quadro de marginalização social. De outro lado, as próprias bases históricas e epistemológicas da Educação Física escolar no país que, inicialmente, corroboraram a exclusão social da população negra (ao rejeitar o corpo negro, promover a estética europeia e propagar ideais higienistas e eugênicos), mas que posteriormente passaram a defender uma perspectiva crítica, comprometida com a inclusão social e a diversidade. Assim, busca-se introduzir o conceito de inclusão social, discutir a demanda da população negra por inclusão social, considerando a Lei 10.639/2003 e ressaltar o compromisso da Educação Física escolar com essa inclusão.
\end{abstract}

Palavras-chave: Educação Física escolar. Inclusão social. População negra.

\begin{abstract}
This paper addresses the issue of black population's historical demand for social inclusion, as well as the commitment of school physical education classes with this demand. In the background, one perspective shows the exclusion of black people in the Brazilian society, resulting from the slavery regime and their struggle to change this scenery of social marginalization. Another perspective approaches the very historical and epistemological bases of school physical education in the country, which initially corroborated the social exclusion of black students (by rejecting the black body, promoting the European aesthetics and propagating hygienist and eugenic ideas), but after some time started to defend a critical perspective, committed with social inclusion and diversity. Thus, the concept of social inclusion is introduced and the demand of the black population for social inclusion is discussed considering the Law $10.639 / 2003$ and highlighting the commitment of school physical education with this inclusion.
\end{abstract}

Keywords: School Physical education. Social Inclusion. Black Population.

Resumen: Se trata de un cuestionamiento acerca de la demanda histórica de la población negra para la inclusión social, así como el compromiso de la educación física escolar con esta demanda. Como temática,

\footnotetext{
* Doutoranda em Ciências Sociais na Universidade Federal de Juiz de Fora (UFJF). E-mail: <vadecastro@hotmail.com>.
} 
por un lado, hay la exclusión de los negros en la sociedad brasileña, debido al régimen de esclavos y su lucha para revertir esta situación de marginación social. Por otro lado, los mismos fundamentos históricos y epistemológicos de la educación física en el país que inicialmente apoyó la exclusión social de la población negra (por rechazar el cuerpo negro, promueven la estética europea y propagan los ideales higienistas y eugenésica), enseguida pasaron a defender un punto de vista crítico, comprometido con la inclusión social y la diversidad. De este modo, se introduce el concepto de inclusión social, se discute la demanda de la población negra para la inclusión social, teniendo en cuenta la Ley 10.639 / 2003 que pone de relieve el compromiso de la educación física escolar con esta inclusión.

Palabras clave: Educación Física. Inclusión social. Población negra.

\section{Introdução}

$\mathrm{Na}$ literatura científica pertinente, não encontramos unanimidade em relação ao conceito de inclusão social. De modo geral, o conceito de inclusão social muitas vezes é trabalhado a partir de seu oposto, o conceito de exclusão social. Assim, de um lado, temos o conceito de exclusão social remetendo à ideia de marginalização de indivíduos e grupos no que tange ao seu direito pleno de participar, contribuir e se beneficiar da vida social - frequentemente, o conceito de exclusão social é associado aos fenômenos da pobreza e sua erradicação (RODRIGUES et al., 1999; LEAL, 2004; SCHWARTZMAN, 2004). De outro lado, temos o conceito de inclusão social, enquanto oposto, remetendo à tentativa de incluir os indivíduos e grupos marginalizados, resgatando seu direito pleno de participar, contribuir e se beneficiar da vida em sociedade. Os conceitos de exclusão e inclusão social são discutidos nas mais diversas esferas da vida social, por exemplo, no mercado de trabalho, na habitação, na tecnologia, no sistema de saúde, no sistema escolar, dentre outras. Nesse sentido, são vários os indivíduos e grupos excluídos dessas esferas, tais como negros, mulheres, portadores de necessidades especiais, dentre outros, que precisam ser incluídos com dignidade.

Embora os conceitos de exclusão e inclusão social muitas vezes sejam considerados imprecisos, em geral, é a parir da ideia de exclusão social que se recomendam políticas de inclusão, isto é, de acesso aos direitos sociais. Temos como exemplo a Declaração de Salamanca (1994), considerada um dos principais documentos mundiais que visam a combater a exclusão social. Embora esse documento seja voltado às crianças portadoras de necessidades especiais, seu ponto central é o combate à exclusão e a defesa de princípios inclusivos. O documento defende, dentre outras coisas, o desenvolvimento de estratégias para promover a inclusão escolar efetiva para todos os alunos, independente de suas características individuais, endossando que a inclusão escolar é indispensável ao exercício dos direitos humanos. Tomando como exemplo a definição gerada a partir da Declaração de Salamanca (1994), Cruz e El Tassa (2012) ressaltam que a noção de inclusão escolar não trata somente da presença dos alunos em sala de aula, mas do atendimento e respeito às suas necessidades particulares a fim de favorecer uma educação de qualidade para todos. Também ressaltam que a inclusão escolar não se refere somente a indivíduos ou grupos que apresentem necessidades educacionais especiais, mas a todos aqueles que apresentem problemas de adaptação de cunho social, cultural ou econômico (CRUZ; EL TASSA, 2012).

Freire (2008) destaca que a inclusão escolar repousa sobre quatro eixos fundamentais. O primeiro eixo trata do direito fundamental. Nesse sentido, a inclusão é uma questão de direitos que assiste a todas as crianças, independentemente de gênero, classe, cor ou outras características individuais e sociais. Enquanto direito fundamental, não pode ser negado a nenhum indivíduo ou grupo. No campo da inclusão social os negros e as mulheres são exemplos de grupos que,

Práxis Educativa, Ponta Grossa, v. 12, n. 2, p. 520-535, maio/ago. 2017 Disponível em: <http://www.revistas2.uepg.br/index.php/praxiseducativa > 
historicamente, foram alvos de discriminações e preconceitos que lhes negaram a igualdade de condições e de oportunidades para a construção de uma vida digna. O segundo eixo trata da necessidade de repensar a diferença e a diversidade. Nesses termos, temos a inclusão como um novo modo de encarar a diferença. Aceitar a diferença implica reconhecer em cada criança distintos ritmos de aprendizagem, interesses, motivações e projetos de vida (FREIRE, 2008).

O terceiro eixo destacado por Freire (2008) trata da necessidade de repensar a escola. Por esse ângulo, a transformação da escola constitui uma ideia central do movimento inclusivo. A escola deve adotar novos modos de funcionamento, mais flexíveis e adequados aos alunos. $\mathrm{O}$ problema não reside mais no aluno, mas sim na forma como a escola está organizada e no modo como funciona. O quarto eixo trata da transformação da sociedade. Nessa perspectiva, para se criar um sistema educativo inclusivo, não basta mudar a escola, uma vez que o sistema é permeável aos valores sociais e culturais dominantes na sociedade. O desenvolvimento de uma educação inclusiva obriga a grandes mudanças organizacionais e funcionais em diferentes níveis do sistema de ensino, mudanças na articulação dos diferentes agentes educativos, bem como na gestão do currículo e da sala de aula (FREIRE, 2008). A articulação entre esses quatro eixos seria fundamental à verdadeira inclusão escolar.

Esse artigo aborda justamente a questão da inclusão social, por meio das aulas de Educação Física escolar. Enquanto componente curricular da educação básica, o objetivo da Educação Física escolar é inserir os alunos na cultura corporal de movimento, privilegiando a inclusão social. De acordo com um dos principais documentos que regem a educação básica no Brasil, Parâmetros Curriculares Nacionais (documento referência elaborado na década de 1990, sob a orientação do Ministério da Educação, reunindo as diretrizes curriculares nacionais para a educação básica), uma das premissas pedagógicas fundamentais da Educação Física escolar é a inclusão de todos os alunos. O professor de Educação Física escolar deve sistematizar seus conteúdos e objetivos de modo a evitar a exclusão ou alienação no que tange à cultura corporal de movimento. Tendo em vista a inclusão social, deve construir um ambiente significativo de aprendizagem, que faça sentido para os alunos e possibilite amplamente sua participação. O professor deve ser flexível e fazer as adequações necessárias em seu plano de ensino, nas regras das atividades, na utilização dos espaços e dos materiais, visando a estimular todo o grupo e a favorecer o princípio da inclusão. Deve-se promover o reconhecimento e a valorização de atitudes não discriminatórias quanto a habilidades, gênero, cor, dentre outras, visando à inclusão de todos os alunos nas práticas da cultura corporal de movimento (BRASIL, 1998).

Posto isso, o objetivo geral desse artigo é problematizar o compromisso da Educação Física escolar com a demanda histórica da população negra por inclusão social. Os objetivos específicos são introduzir o conceito de inclusão social, discutir a demanda da população negra por inclusão social, vide Lei $\mathrm{n}^{\circ} 10.639 / 2003$, e ressaltar o compromisso da Educação Física escolar com essa inclusão. No Brasil, a demanda da população negra por inclusão social advém das distinções e desigualdades raciais presentes na sociedade contemporânea, herdadas do regime escravocrata. Essas distinções e desigualdades fazem-se marcantes, com perversas consequências econômicas, sociais, culturais e políticas para a população afro-brasileira e para o país. Tais distinções e desigualdades são amplamente apontadas pela literatura científica. Paixão (2006), por exemplo, destaca o modelo assimétrico de relações raciais, a discriminação agravada sobre as mulheres negras, o cenário de genocídio sobre os jovens negros, as desigualdades raciais nos indicadores de escolaridade, etc. Autores como Florestan (1965); Hasenbalg (1979); Henriques (2001); Silvério (2002); Heringer (2002); Theodoro (2008); Lima (2010); Gomes (2011) dentre outros, são relevantes no que tange à análise e à produção de dados sobre os indicadores sociais da população negra, políticas públicas para o enfrentamento da desigualdade racial e do racismo, dentre outras questões referentes à situação dos negros no Brasil.

Práxis Educativa, Ponta Grossa, v. 12, n. 2, p. 520-535, maio/ago. 2017 Disponível em: <http://www.revistas2.uepg.br/index.php/praxiseducativa > 
Frente ao quadro de marginalização social dos negros no país, nos últimos anos, várias políticas e ações afirmativas têm sido desenvolvidas no intuito de promover e acelerar a sua tardia inclusão na sociedade brasileira, especialmente, na esfera da educação. Um exemplo foi a promulgação da Lei $\mathrm{n}^{\circ}$ 10.639/2003, que tornou obrigatório o ensino de conteúdos relacionados à história e às culturas africana e afro-brasileira nas escolas públicas e particulares de educação básica. A Lei no 10.639/2003 acrescentou à Lei de Diretrizes e Bases da Educação Nacional (LDB, $\mathrm{n}^{\circ}$ 9.394/96) dois artigos: o 26-A, que estabelece o ensino sobre a história e cultura afrobrasileira, a história da África e a dos africanos, a luta dos negros no Brasil, a cultura negra brasileira e o negro na formação da sociedade nacional; e o artigo 79-B, que inclui no calendário escolar o Dia Nacional da Consciência Negra, comemorado em 20 de novembro (BRASIL, 2007).

Embora a Lei 10.639/2003 estabeleça que os conteúdos referentes à história e cultura africana e afro-brasileira sejam ministrados no âmbito de todo o currículo escolar, ela enfatiza as áreas de educação artística, literatura e história, subestimando as potencialidades das demais áreas que compõe o currículo escolar de contribuírem com o ensino desses conteúdos. Contudo, apesar da ênfase nessas áreas, de modo geral, a Lei determina que o ensino desses conteúdos seja ministrado no âmbito de todo o currículo escolar. Ainda assim, fica a cargo das escolas e dos professores incorporarem tais conteúdos às suas práticas pedagógicas. No entanto, muitos ainda não o fazem, seja por falta de formação adequada, desinteresse, ou mesmo por preconceitos e, com isso, a maioria dos alunos permanece sem conhecer o legado histórico, social e cultural dos africanos e seus descendentes no país. Assim, defende-se o compromisso da Educação Física escolar no enfrentamento e superação desse problema. Acredita-se que a Educação Física escolar tem amplas possibilidades pedagógicas de valorização e reconhecimento da identidade negra, tendo muito a contribuir com a inclusão social desse grupo. É necessário que os professores tenham atitude.

\section{A demanda da população negra por inclusão social}

Para melhor compreender a demanda da população negra por inclusão social, antes é preciso compreender o contexto em que se organizam as relações étnico-raciais na sociedade brasileira, resgatando a perversa história de como os negros foram trazidos para o país e de como foram tratados desde então. Como já se sabe, entre os séculos XVI e XIX, milhares de negros foram traficados da África para o Brasil, sendo arbitrariamente desenraizados de sua terra natal, escravizados, coisificados, mal tratados, degradados moralmente e explorados em sua mão de obra. A exploração da mão de obra dos negros escravizados movimentou a economia brasileira por mais de trezentos anos, entre 1500 e 1800. Somente ao final do século XIX que o regime escravocrata entrou legalmente em declínio no país, especialmente, em razão do advento da modernidade, do capitalismo e do regime republicano (NABUCO, 1988).

Nesse contexto, apesar das tentativas de resistência por parte dos negros escravizados (por meio de revoltas, fugas organizadas, formação de quilombos, etc.), bem como a solidariedade dos abolicionistas, a extinção da escravidão aconteceu de forma lenta e gradual, por meio da promulgação de diversas Leis ${ }^{1}$. Somente em 13 de maio de 1888, o regime escravocrata foi legalmente abolido no país, com a assinatura da Lei Áurea. No entanto, a abolição da escravatura não representou uma ruptura, devido a sua incapacidade de transformar as profundas desigualdades econômicas e sociais, bem como responder ao racismo que se seguiu para manter o

\footnotetext{
${ }^{1}$ Lei Eusébio de Queiros (1850), que determinou o fim do tráfico de escravos para o Brasil; a Lei dos sexagenários, que libertou os escravos com mais de 65 anos (1885); a Lei do Ventre Livre (1871), que declarou livres os filhos de escravos nascidos a partir da promulgação da Lei (BRASIL, 1888).
}

Práxis Educativa, Ponta Grossa, v. 12, n. 2, p. 520-535, maio/ago. 2017 Disponível em: <http://www.revistas2.uepg.br/index.php/praxiseducativa $>$ 
status quo. Nessa manutenção, a relação senhor/escravo cedeu lugar à relação branco/negro, ambas hierarquizadas. A Lei Áurea é apresentada como grandeza da Nação brasileira, mas a realidade social dos negros no período que se seguiu permaneceu problemática (MUNANGA, 2015).

O período que se seguiu à abolição da escravidão foi marcado pela aceleração do desenvolvimento econômico e pela abertura de novas oportunidades de ascensão social, porém não para os ex-escravos, ou mesmo para a população negra livre, excluídos dos setores mais dinâmicos da economia urbana e relegados às margens do sistema produtivo (THEODORO, 2008). Após a abolição, os negros foram abandonados à própria sorte, sendo encarregados de se reeducar e de se transformar a fim de corresponder aos novos padrões sociais criados pelo advento do trabalho livre, do capitalismo e do regime republicano. Porém, uma vez que, no Brasil, os negros foram socializados em um regime escravocrata, faltava-lhes, nessa nova ordem social, tanto a experiência e o domínio de técnicas sociais e culturais adequadas para a sua devida integração na sociedade de classes, quanto as oportunidades sociais necessárias para tal. Nesse processo, a anomia social, a pauperização e a integração precária da população negra, combinadas entre si, culminaram em um padrão de exclusão econômica, social e cultural dos negros na sociedade brasileira (FERNANDES, 1965).

A ordem escravocrata persistiu na mentalidade, no comportamento e na organização das relações sociais mesmo após a abolição, colidindo com os fundamentos econômicos, legais e morais da nova ordem social (FERNANDES, 1965). O racismo, que nasce no país associado à escravidão, consolida-se mesmo após a abolição, com base em teses sobre a inferioridade biológica dos negros, difundidas no país como matriz para a interpretação do desenvolvimento nacional. As interpretações higienistas e eugênicas, amplamente adotadas pela sociedade brasileira, vigoraram entre o final do século XIX e início do século XX e estiveram presentes na base da formulação de políticas públicas que contribuíram, efetivamente, para o aprofundamento das desigualdades raciais no país (THEODORO, 2008).

Nesse período, as teorias raciais de cunho positivo e evolucionista ganharam força no Brasil, principalmente na análise dos problemas relacionados ao desenvolvimento nacional. Em meio a um contexto caracterizado pelo fim da escravidão e pelo estabelecimento de um novo projeto político e econômico para o país, as teorias raciais se apresentaram como um modelo teórico viável de interpretação nacional para as elites. Essas teorias foram fundamentais aos jogos de interesses que se configuravam, harmonizando-se com ideais políticos, os quais defendiam a submissão ou mesmo a eliminação das raças tidas como inferiores. Desta forma, as correntes higienistas e eugênicas influenciaram profundamente a política social nesse período, contribuindo com a desigualdade racial (SCHWARCZ, 1993). Temos como exemplo as políticas de incentivo à imigração europeia, adotadas pelo governo brasileiro ao final do século XIX e início do século XX, tidas como tentativas explícitas de "branquear" a população nacional. A força de trabalho dos imigrantes europeus foi contratada preferencialmente, em detrimento dos negros, tanto na agricultura, como nas indústrias que estavam sendo implantadas nas principais cidades do país (HERINGER, 2002).

A partir da década de 1930, o "mito da democracia racial" foi amplamente difundido no país, generalizando uma falsa consciência sobre as relações raciais, fomentando um conjunto de convicções na pacífica convivência entre as raças, na ideia de que os negros não têm problemas no Brasil, de que não existem distinções raciais, de que as oportunidades de acumulação de riqueza, prestígio social e poder são igualmente acessíveis a todos, dentre tantas outras ideias erroneamente propaladas, que negaram a realidade racial pungente, dificultando seu enfrentamento e superação. Logo, as convicções de que as relações sociais entre negros e brancos 
corresponderiam a uma democracia racial não passaram de um mito, que foi um grande empecilho ao desenvolvimento da ordem social competitiva e democrática, pois mascarou a verdadeira situação dos negros no país, dificultando não somente a sua tomada de consciência, mas também a intervenção organizada na sociedade por meio de políticas públicas (FERNANDES, 1965). Paixão (2006) ressalta que, nesse período, a tão exaltada mestiçagem foi o modo elegante pelo qual a elite euro-descendente compreendeu o processo de transição étnicodemográfica do povo brasileiro, rumo a uma sociedade totalmente livre das marcas negra e indígena.

Após a década de 1930, as relações étnico-raciais sofreram importantes mudanças. Nesse sentido, alguns impulsos favoráveis à maior compreensão e tolerância racial foram fundamentais, abrindo caminhos para a livre discussão e para a luta, protagonizada pelos próprios negros, através de movimentos sociais (FERNANDES, 1965). Nesse período, buscando reverter o quadro de marginalização social, os negros instituíram no país movimentos de mobilização, criando vários grupos, tais como grêmios, clubes e associações. Esses grupos, referidos genericamente como Movimento Negro, por meio de diversas organizações, empreenderam lutas em favor da população negra, tendo em vista amenizar os problemas provenientes do preconceito, da discriminação e da desigualdade racial. Porém, entre os anos 1960 e 1970, com a ditadura militar, muitas formas de liberdade intelectual e atividade política foram suprimidas, dificultando a organização dos movimentos sociais, dentre os quais, o Movimento Negro (HERINGER, 2002; DOMINGUES, 2007).

Nos anos 1980, com a promulgação da nova Constituição da República em 1988, foi instituído o Estado Democrático e de Direitos, no qual, dentre os principais fundamentos, encontra-se a promoção do bem estar de todos, sem preconceitos de origem, sexo, cor, idade e quaisquer outras formas de discriminação. Assim, a questão racial entrou para pauta da agenda pública nacional. O Movimento Negro passou a dialogar mais com o Estado e com a sociedade civil, angariando vitórias fundamentais à democratização dos seus direitos. Como consequência, nas últimas décadas, diversos instrumentos e políticas de promoção da igualdade racial têm sido implantados e intensificados por todo o país (HERINGER, 2002; DOMINGUES, 2007).

Ao final do século XX e início do século XXI, assistimos à implementação de medidas como a Lei 7.716/1989, que define os crimes resultantes de preconceito de raça e de cor; a Lei $\mathrm{n}^{\circ}$ 10.678/2003, que cria a Secretaria de Políticas de Promoção da Igualdade Racial (SEPPIR); a Lei $\mathrm{n}^{\mathrm{o}} 10.639 / 2003$, que torna obrigatório o ensino de conteúdos relacionados à história e às culturas africana e afro-brasileira nas escolas públicas e privadas de educação básica; a Lei no 11.645/2008, que estabelece as diretrizes e bases da educação nacional para incluir no currículo oficial da rede de ensino a obrigatoriedade da temática história e cultura afro-brasileira e indígena; a Lei $\mathrm{n}^{\circ}$ 12.288/2010, que institui o Estatuto da Igualdade Racial; a Lei $n^{\circ} 12.711 / 2012$, que garante aos negros a reserva de $50 \%$ das matrículas por curso e turno nas universidades e institutos federais de educação, ciência e tecnologia; a Lei $\mathrm{n}^{\circ}$ 12.990/2014, que prevê a reserva de $20 \%$ das vagas oferecidas nos concursos públicos federais aos negros, dentre outras. Tais medidas devem ser consideradas grandes conquistas na luta pela igualdade racial no Brasil, embora as desigualdades raciais no país permaneçam marcantes. Paixão (2006) alerta que o enfrentamento das questões derivadas das relações étnicas e raciais encontra-se entre os maiores desafios da humanidade no século XXI. Desta forma, a luta contra o racismo, a discriminação racial e todas as formas de intolerância em relação às diferenças, deve ser assumida como uma causa de todos.

Nas primeiras décadas do século XXI, o Brasil vem experimentando um processo de desenvolvimento econômico, acompanhado de maior inclusão social, ainda que longe do tipo ideal. É possível verificar mudanças nas condições de vida da população negra, as quais resultam, 
em grande parte, de iniciativas governamentais que apoiam a promoção da igualdade racial. Tais iniciativas perpassam por políticas socioeconômicas, como por exemplo, a expansão do mercado de trabalho formal, a ampliação da cobertura da previdência social e dos programas de redução da pobreza. Essas iniciativas também perpassam por ações para o atendimento a direitos básicos da população negra, bem como por ações afirmativas que visam à promoção da igualdade de oportunidades, como é o caso das cotas para negros no acesso ao ensino público superior (IPEA, 2011).

De acordo com o Instituto de Pesquisa Econômica Aplicada (IPEA), a análise da situação social do país revela que a melhoria dos indicadores sociais, em muitos casos, ocorreu de modo mais pronunciado para a população negra. Dentre esses indicadores, destaca-se a significativa redução do percentual dos negros que vivem em situação de pobreza e o expressivo aumento dos que se situam nas faixas médias de renda e nos níveis mais altos de escolaridade. No entanto, embora a população negra tenha deixado de se concentrar majoritariamente entre os mais pobres, seu nível de renda per capita familiar permanece menor que o nível de renda per capita familiar da população branca. Apesar do evidente avanço nas condições de inserção econômica e social, ainda persistem as desigualdades que colocam os negros em desvantagem em relação aos brancos em vários indicadores sociais. Essas desigualdades raciais se devem às enormes desvantagens acumuladas pelo segmento negro ao longo da história. Diante disso, a implementação de políticas de promoção da igualdade racial desafia o governo e a sociedade civil (IPEA, 2011).

Dentre as medidas que visam à inclusão social da população negra, o presente artigo chama a atenção para a Lei 10.639/2003. Essa Lei é uma importante medida que visa a ressarcir os afrodescendentes pelos danos psicológicos, culturais, econômicos, sociais e políticos sofridos durante e após o regime escravocrata. É uma demanda da população negra por reconhecimento, inclusão, valorização, justiça e equidade (BRASIL, 2004). A Lei 10.639/2003 é considerada uma importante medida afirmativa e seu lócus central é a educação básica. Como enfatizado por Gomes (2011), as medidas afirmativas são políticas, projetos e práticas, públicas ou privadas, que têm por objetivo superar as desigualdades que afligem determinados grupos sociais ao longo da história, tais como negros, mulheres, portadores de necessidades especiais, homossexuais, indígenas, dentre outros. Logo, a Lei $\mathrm{n}^{\mathrm{o}}$ 10.639/2003 é considerada uma medida de ação afirmativa, uma vez que tem como objetivo afirmar o direito à diversidade étnico-racial na educação escolar, bem como afirmar a história, a memória e a identidade dos negros e seus descendentes no país. Ao introduzir a discussão sobre as relações étnico-raciais na escola, a referida Lei fomenta mudanças significativas na educação, especialmente em relação ao respeito e ao reconhecimento da diversidade étnico-racial (GOMES, 2011).

Desde a promulgação da Lei 10.639/2003, o Ministério da Educação vem executando uma série de ações para implementá-la, tais como o oferecimento de cursos gratuitos de formação continuada, presenciais e à distância, sobre a temática da diversidade étnico-racial para professores de todo o país; publicações de material didático; o fortalecimento dos Núcleos de Estudos Afro-brasileiros, constituídos nas instituições públicas de ensino, através do Programa UNIAFRO; a realização de Fóruns Estaduais e Municipais de Educação e Diversidade Étnicoracial; dentre outras medidas que visam à implementação da Lei. Além dessas iniciativas, as Diretrizes Curriculares Nacionais para Educação das Relações Étnico-raciais e para o Ensino da História e Culturas Afro-brasileira e Africana (Parecer CNE/CP n ${ }^{\circ} .03$ de 10 de março de 2004), estabelecem as orientações quanto aos conteúdos a serem trabalhados em todos os níveis e modalidades de ensino (BRASIL, 2009). Apesar dessas ações, trabalhar a temática racial no currículo escolar permanece como um grande desafio, permeado por conflitos, contradições, desinformação, preconceitos e desinteresse.

Práxis Educativa, Ponta Grossa, v. 12, n. 2, p. 520-535, maio/ago. 2017 Disponível em: <http://www.revistas2.uepg.br/index.php/praxiseducativa $>$ 
Segundo os principais documentos que regem a educação básica ${ }^{2}$, a escola deve ser um lugar privilegiado de inclusão social, devendo promover o respeito às diferenças, bem como o atendimento à pluralidade e à diversidade cultural, visando aos direitos humanos. A inclusão social deve ser exercitada em compromisso com a equidade e a qualidade. No âmbito das relações étnico-raciais, o ensino da cultura africana e afro-brasileira visa a promover a inclusão da população negra e a ampliar o leque de referências culturais de toda a população escolar, contribuindo para a mudança de suas concepções de mundo, transformando os conhecimentos comuns veiculados pelo currículo e contribuindo para a construção de identidades plurais e solidárias.

Posto isso, ressalta-se que a Educação Física, enquanto componente curricular, tem amplas possibilidades pedagógicas de abordar as culturas africanas e afro-brasileiras, tendo um papel muito importante no combate à discriminação racial e na promoção da inclusão social dos negros. É indispensável que o professor tenha consciência de sua responsabilidade, buscando desmistificar as ideologias racistas que prevalecem no senso comum, conduzindo seus alunos a uma nova compreensão das questões raciais, bem como à transformação de suas consciências, promovendo o reconhecimento e o respeito às diferenças. O professor de Educação Física escolar pode, por exemplo, acrescentar ao conteúdo de suas aulas atividades como danças, jogos, brincadeiras, dentre outras, de origens africana e afro-brasileira, destacando sua importância na construção da identidade dos grupos e da própria identidade nacional. Nesse momento de valorização da cultura negra, certamente estará contribuindo para a preservação e transmissão dos valores culturais e memória desse grupo. Os professores, em geral, precisam refletir de forma crítica sobre a questão da discriminação racial, compreendendo suas raízes históricas e suas contradições, buscando superá-las em sua prática pedagógica. Para que seja um agente de transformação ativo no combate ao preconceito e à discriminação racial é indispensável que esse profissional, sendo negro ou não, desmistifique suas próprias ideologias e pré-conceitos (GONÇALVES, 1991).

\section{O compromisso da Educação Física escolar com a inclusão social da população negra}

Para melhor compreendermos o compromisso da Educação Física escolar com a inclusão social da população negra, além de considerarmos a exclusão social dos negros na sociedade brasileira, decorrente do regime escravocrata, bem como sua luta histórica para reverter esse quadro de marginalização social, por exemplo, por meio da Lei 10.639/2003, como exposto anteriormente, também é indispensável considerarmos as próprias bases históricas e epistemológicas da Educação Física na escola brasileira. Assim, será possível perceber como as bases desta disciplina, inicialmente, corroboraram a exclusão social da população negra (ao rejeitar o corpo negro, promover a estética europeia e propagar ideais higienistas e eugênicos), posteriormente passando a defender uma perspectiva crítica, comprometida com a inclusão social e a diversidade.

No Brasil, a Educação Física foi incorporada oficialmente ao currículo escolar na segunda metade do século XIX, especificamente em 1851, com a reforma Couto Ferraz (DARIDO, 2003). Influenciada por ideais europeus, a Educação Física no país emerge da articulação entre instituições médicas - higienistas e eugênicas - tendo por objetivo a prevenção da saúde e o melhoramento da "raça brasileira"; instituições militares, visando ao desenvolvimento do esporte,

\footnotetext{
2 Documentos como a Lei no 9.394, que estabelece as Diretrizes e Bases da Educação Nacional (LDB); Parâmetros Nacionais Curriculares; Diretrizes Curriculares Nacionais para a Educação Básica, dentre outros.

$<$ http:/ / portal.mec.gov.br/index.php?option=com_content\&view $=$ article\&id $=293 \&$ Itemid $=358>$
}

Práxis Educativa, Ponta Grossa, v. 12, n. 2, p. 520-535, maio/ago. 2017 Disponível em: <http://www.revistas2.uepg.br/index.php/praxiseducativa $>$ 
do patriotismo, da competitividade, da disciplina e obediência; e instituições pedagógicas, cujos objetivos remetem não somente ao aprimoramento físico, mas também ao aprimoramento intelectual dos alunos, de uma forma ampla e crítica (ALBUQUERQUE, 2009).

Ao final do século XIX e início do século XX, as correntes médicas higienistas e eugênicas vigoraram no Brasil, direcionando, dentre outras coisas, os princípios da Educação Física escolar. Nesse período, foram importadas diversas teorias europeias para interpretar o desenvolvimento nacional, dentre as quais, as teorias higienistas e eugênicas, cujo eixo central era a preocupação com a saúde da população. No Brasil, essas teorias foram adotadas como estratégias para o embranquecimento da população, defendendo medidas como a esterilização dos negros, a proibição de casamentos inter-raciais e o favorecimento da imigração europeia. Para essas teorias, a miscigenação das raças era tida como degenerativa e o higienismo e a eugenia seriam ferramentas científicas eficazes, capazes de promover a regeneração racial e colocar o país nos trilhos do progresso e do desenvolvimento. As correntes higienistas e eugênicas influenciaram profundamente a prática da Educação Física escolar no país (GÓIS JÚNIOR; LOVISOLO, 2005).

Ao examinar a inserção da Educação Física nas escolas públicas do estado de Minas Gerais, bem como os ordenamentos legais para a prática da Educação Física escolar no país, Vago (2000) destaca que no início do século XX, além de promover o aperfeiçoamento da "raça brasileira", tida como fraca e inapta ao trabalho em decorrência da miscigenação, que foi considerada a própria causa de sua degeneração, a Educação Física na escola também buscava promover a saúde e endireitar os corpos das crianças, assumindo a missão de educá-los e tornálos eficientes e produtivos para o mundo do trabalho. Assim, a Educação Física foi inicialmente apresentada como recurso para a regeneração da "raça brasileira", bem como para preparação dos corpos para o mundo do trabalho, contribuindo com o projeto social republicano (VAGO, 2000).

No Brasil, o período compreendido entre os anos de 1937 e 1945, chamado de Estado Novo, foi marcante na história do país e da própria Educação Física escolar. O governo de Getúlio Vargas, que tinha como proposta fortalecer a indústria e o nacionalismo, visava à implantação de um sistema educacional que suprisse esses objetivos. Nesse contexto, a Educação Física passou a exercer um papel mais relevante como um canal de propagação das ideologias da época. A partir da constituição de 1937, a Educação Física foi instituída como uma disciplina escolar obrigatória em âmbito federal. Tal processo implicou em uma maior demanda por profissionais que atuassem nessa área e, desta forma, a questão da formação de professores entrou para a agenda política nacional (ALBUQUERQUE, 2009).

Ao final da década de 1940, frente à influência dos Educadores da Escola Nova, houve diversas tentativas de estabelecer o encontro da Educação Física com a pedagogia. Nesse período, deu-se início a um grande processo de pedagogização, porém ainda sem romper totalmente com a organização didática comprometida com parâmetros militares. Esse movimento defendia que a Educação Física escolar deveria ter por base o respeito à personalidade dos alunos e a promoção de uma educação integral. No entanto, passou a ser reprimido com a instauração da ditadura militar no país, em 1964. Nas décadas seguintes, os governos militares investiram nos esportes como um sustentáculo ideológico para o desenvolvimento e êxito do país. A Educação Física escolar passou a ser pensada como sinônimo de desporto. A influência do esporte se sobressaiu no sistema educacional enquanto objetivo e conteúdo da Educação Física (DARIDO, 2003).

A partir da década de 1970, o Decreto no 69.450, vigente de 1971 a 1996, concebeu a Educação Física escolar como atividade responsável por desenvolver e aprimorar as forças físicas,

Práxis Educativa, Ponta Grossa, v. 12, n. 2, p. 520-535, maio/ago. 2017 Disponível em: <http://www.revistas2.uepg.br/index.php/praxiseducativa > 
valores morais e cívicos, habilidades psíquicas, atitudes de respeito mútuo, solidariedade e coletividade, visando à formação integral dos alunos (GUIMARÃES et al., 2001). Na década de 1980, esse modelo passou a ser cada vez mais contestado, abatendo-se uma profunda crise de identidade sobre os princípios da Educação Física escolar. Nesse contexto, diversas abordagens teóricas se destacam, visando a uma Educação Física articuladora das dimensões humanas. Tais abordagens têm em comum a tentativa de romper com o modelo mecanicista, esportivista e tradicional. Dentre essas abordagens, podemos destacar a Humanista, Fenomenológica, Psicomotricidade, Cultural, Desenvolvimentista, Interacional-Construtivista, Crítico-Superadora, Sistêmica, Crítico-Emancipatória e a abordagem dos Parâmetros Curriculares Nacionais, a qual, atualmente, organiza a Educação Física escolar no país (DARIDO, 2012).

Nos anos 1990, com a promulgação da Lei de Diretrizes e Bases da Educação Nacional (LDB n ${ }^{\circ}$ 9.394/96), a Educação Física foi integrada à proposta pedagógica da escola como um componente curricular da educação básica, ajustando-se às faixas etárias e às necessidades da população escolar. Nesse período, os Parâmetros Curriculares Nacionais passaram a direcionar a Educação Física escolar, segundo a cultura corporal de movimento (GUIMARÃES et al., 2001). De acordo com os Parâmetros Curriculares Nacionais, cabe à Educação Física escolar a tarefa de transmitir às novas gerações um vasto patrimônio cultural da humanidade, ligado aos jogos, esportes, lutas, danças e ginásticas, dentre outras práticas que constituem a cultura corporal (BRASIL, 1998). Assim, tornou-se dever da Educação Física escolar proporcionar a vivência da cultura corporal, com enfoque nas dimensões culturais, simbólicas, inclusivas, críticas, de lazer e de saúde (DARIDO, 2012).

Segundo Soares et al. (1992), no âmbito da Educação Física escolar, a cultura corporal é uma reflexão pedagógica acerca das representações de mundo construídas pelos homens no decorrer da história, exteriorizadas por meio da expressão corporal. A cultura corporal é o resultado de práticas corporais historicamente produzidas e acumuladas pela humanidade, desde jogos, lutas, ginásticas, danças, esportes, dentre outras. Deve ser transmitida aos alunos nas aulas de Educação Física escolar, contribuindo para a afirmação de valores e identidades. A afirmação de valores e identidades é condição objetiva para a construção da consciência, para o engajamento deliberado na luta pela transformação da sociedade e para a conquista da hegemonia popular. Desta forma, os conteúdos da cultura corporal devem ser vivenciados nas aulas de Educação Física, possibilitando aos alunos a compreensão da sociedade, visando a superar o senso comum, permitindo a constatação, interpretação, compreensão, explicação e crítica acerca da cultura corporal (SOARES et al., 1992).

Assim, a partir dos anos 1990, a Educação Física escolar passa a ser entendida como uma área de conhecimento da cultura corporal de movimento, cujo objetivo é introduzir os alunos nesta cultura, visando a formar cidadãos críticos, capazes de reproduzir e transformar a cultura corporal. A Educação Física escolar deve localizar nas modalidades da cultura corporal (jogos, esportes, danças, ginásticas, lutas e etc.) seus benefícios e possibilidades de comunicação, expressão de sentimentos e emoções, lazer e saúde. Para tanto, a Educação Física escolar deve proporcionar oportunidades a todos os alunos para desenvolverem suas potencialidades de forma democrática, visando ao seu aprimoramento como ser humano (BRASIL, 1998). Assim, os Parâmetros Curriculares Nacionais, a partir de seus princípios de inclusão e diversidade, passam a propor uma Educação Física escolar voltada a todos os alunos, sem discriminação, bem como o relacionamento das atividades da Educação Física com os grandes problemas da sociedade brasileira, sem perder de vista o seu papel de integrar o cidadão na esfera da cultura corporal (DARIDO et al., 2001). 
É reconhecida a distância entre as concepções teóricas e a prática real nas aulas de Educação Física escolar. Porém, é necessário um esforço do professor para colocar em prática os princípios da disciplina, especialmente, o princípio da inclusão. A inclusão de todos os alunos na cultura corporal de movimento é um dever da Educação Física escolar e um direito de todos os alunos, independente de suas características particulares. Frente a isso, longe de negar a demanda de outros grupos por inclusão social, esse artigo argumenta especificamente sobre a demanda da população negra por inclusão, vide Lei 10.639/2003, bem como o compromisso da Educação Física escolar com essa demanda, uma vez que as próprias bases históricas e epistemológicas da Educação Física escolar no Brasil mostram que essa disciplina favoreceu interesses higienistas e eugênicos, contribuindo com a propagação da ideologia racial.

Conforme enfatizado por Silva e Moreira (2009), as bases históricas e epistemológicas da Educação Física escolar têm forte referencial nas teorias higienistas e eugênicas, formuladas e difundidas ao final do século XIX e início do século XX. A Educação Física foi utilizada como estratégia na difusão e organização dessas práticas, que tinham como modelo um corpo perfeito, saudável e equilibrado organicamente. Essa concepção adquiriu grande importância na construção da ideologia racial brasileira e suas matrizes racistas. Já a esportivização, por sua vez, ao abraçar a ideia de superioridade branca, apoiada na imagem corporal helênica e mitologicamente ambicionada, também relegou o corpo negro. A história e epistemologia da Educação Física escolar no país apontam para o distanciamento do corpo negro, bem como para a repercussão da cultura corporal europeia dentro da escola (SILVA; MOREIRA, 2009).

Nos últimos anos, as reflexões sobre a cultura corporal afro-brasileira nas aulas de Educação Física escolar têm sido aprofundadas pelo campo crítico da disciplina, que defende essa manifestação da cultura popular brasileira como uma atividade curricular a ser trabalhada na escola. Com a Lei 10.639/2003, que tornou obrigatório o ensino da história e cultura africana e afro-brasileira nas escolas, crescem os debates e as experiências de inclusão da cultura afrobrasileira nas aulas de Educação Física escolar. Historicamente, a escola e seus componentes curriculares compactuaram, implícita e explicitamente, com a dominação e a inculcação de valores dominantes. Desta forma, enquanto que as teorias e práticas de origem europeias eram amplamente disseminas em todo o Brasil, direcionando os princípios da Educação Física escolar, as práticas da cultura corporal afro-brasileira eram proibidas e criminalizadas (CORREAA, 2012).

Posto isso, defende-se que o professor de Educação Física escolar deve organizar o conteúdo de suas aulas de forma crítica, tendo em vista a demanda da população negra por inclusão social. É importante enfatizar que não se trata de sobrepor as culturas africana e afrobrasileira às demais culturas, mas sim de fazer jus à parte que cabe aos africanos e aos afrodescendentes, garantindo a transmissão de sua herança cultural, especialmente, sua cultura corporal de movimento. Essa temática deve ser introduzida sistematicamente nas aulas, promovendo uma reflexão crítica, centrada na inclusão, na diversidade cultural, no respeito às diferenças e no combate ao preconceito e discriminação racial. Todavia, depende do interesse, da criatividade e da disposição do professor em pesquisar atividades visando a enriquecer as aulas. Infelizmente, nota-se que ainda há poucas publicações sobre a Educação Física escolar e a temática racial.

Como pontuado por Bonfim (2010), no âmbito da Educação Física escolar, a inclusão social deve ser entendida como um processo, uma construção coletiva, que busca a superação da discriminação, do preconceito, da intolerância, das desigualdades e dos conceitos estereotipados. Inclusão social deve ser uma filosofia de trabalho e, para que ela exista, é preciso ter comprometimento com a causa das minorias, dos menos favorecidos e dos excluídos. Nesse sentido, Bonfim (2010) defende que a capoeira é uma excelente prática na promoção da inclusão

Práxis Educativa, Ponta Grossa, v. 12, n. 2, p. 520-535, maio/ago. 2017 Disponível em: <http://www.revistas2.uepg.br/index.php/praxiseducativa > 
e resgate da cidadania. A capoeira vem promovendo a inclusão de pessoas que, até bem pouco tempo, estavam distantes e separadas da sua prática, como negros, mulheres e portadores de necessidades especiais (BONFIM, 2010). Porém, é preciso ressaltar que um dos maiores desafios a ser vencido é o de trabalhar com a temática racial de forma sistematizada e não somente introduzindo elementos isolados nas aulas.

Muitos professores de Educação Física escolar têm usado a capoeira como meio de trabalhar a inclusão social e a Lei 10.639/2003. Ao analisar a temática da diversidade racial e a Educação Física escolar na Revista Brasileira de Ciências do Esporte, no período de 1979 a 2013, considerando a criação dos Parâmetros Curriculares Nacionais (PCN) e a homologação da Lei Federal $n^{\circ} 10.639 / 2003$, Sales e Almeida (2015) constatam a predominância da capoeira nas produções, tanto envolvendo, quanto não envolvendo, o contexto escolar. Os autores ressaltam a pouca valorização de outras expressões da cultura negra que apresentam dimensões valiosas para a contextualização da corporeidade na Educação Física. Por fim, corroborando Sales e Almeida (2015), a importância da problemática esboçada na Lei 10.639/2003 deve ser uma problemática essencial para a Educação Física escolar, que teve sua história ligada ao higienismo e eugenia racial. Frente a isso, a Educação Física escolar tem o compromisso de inserir os alunos na cultura corporal africana e afro-brasileira, resgatando essas práticas que por muito tempo foram relegadas na sociedade. Para tanto, o professor deve fazê-lo de forma a promover a inclusão social dos negros e incentivar o respeito à diversidade.

\section{Considerações finais}

Esse artigo buscou problematizar o compromisso da Educação Física escolar com a inclusão social da população negra. Para tanto, argumentou sobre a histórica exclusão social dos negros na sociedade brasileira, fruto do regime escravocrata, bem como sua luta para reverter esse quadro de marginalização social. Argumentou também sobre as bases históricas e epistemológicas da Educação Física escolar no país, que inicialmente, corroboraram a exclusão social da população negra - ao preterir o corpo negro, sua memória, história e sentidos - mas que posteriormente passaram a defender uma perspectiva crítica, comprometida com a inclusão social, a diversidade e o respeito aos direitos humanos.

Ressalta-se que, embora esse artigo tenha utilizado como recorte o compromisso da Educação Física escolar com a inclusão social dos negros, defende-se que a Educação Física escolar deve estar comprometida com a inclusão social de todos os alunos, com o respeito à diversidade e com o exercício da cidadania. Nota-se que grande parte dos trabalhos que versam sobre Educação Física escolar e inclusão social estão voltados, principalmente, para a inclusão dos portadores de necessidades especiais. Defende-se que é preciso compreender a inclusão social de forma ampla, abrangendo os diversos indivíduos e grupos excluídos da sociedade, desde os portadores de necessidades especiais, os negros, os indígenas, as mulheres, dentre outros, devendo promover uma inclusão social que garanta o acesso de todos e considere a diversidade humana, social, cultural e econômica dos grupos historicamente excluídos. Conforme os argumentos apresentados ao longo do artigo, embasados pelos documentos oficiais e pela literatura científica pertinente, a Educação Física escolar tem um grande compromisso com a inclusão social de todos. 


\section{Referências}

ALBUQUERQUE, L. R. A constituição histórica da Educação Física no Brasil e os processos da formação profissional. In: Congresso Nacional de Educação Educere, 9 - Encontro Sul Brasileiro de Psicopedagogia, 3., 2009, Curitiba-PR. Anais... Curitiba-PR: PUC-PR, 2009. p. 2244-2258.

BONFIM, G. C. S. A prática da capoeira na Educação Física e sua contribuição para a aplicação da lei 10.639 no ambiente escolar: a capoeira como meio de inclusão social e da cidadania. In: Congresso Nordeste de Ciências do Esporte, 3., Fortaleza-CE. Anais... Fortaleza-CE: UFC, 2010. p. 1-12.

BRASIL. Jornal do Senado. Rio de Janeiro, 14 de maio de 1888. Disponível em: $<$ http://www.senado.gov.br/noticias/jornal/arquivos_jornal/arquivosPdf/encarte_abolicao.pdf >. Acesso em: 18 jul. 2015.

BRASIL. Lei $\mathbf{n}^{\mathbf{0}}$ 7.716, de 05 de janeiro de 1989. Disponível em: <http://www.planalto.gov.br/ccivil_03/leis/17716.htm>. Acesso em: 14 ago. 2015.

BRASIL. Declaração de Salamanca e Linha de Ação Sobre Necessidades Educativas Especiais. Brasilia: CORDE, $1994 . \quad$ Disponível em <http://portal.mec.gov.br/seesp/arquivos/pdf/salamanca.pdf>. Acesso em: 20 out. 2016.

BRASIL. Lei $\mathbf{n}^{\mathbf{0}}$ 9.394, de 20 de dezembro de 1996. Disponível em: <http://www.planalto.gov.br/ccivil_03/LEIS/L9394.htm>. Acesso em: 14 ago. 2015.

BRASIL. Ministério de Educação e do Desporto. Parâmetros Curriculares Nacionais: terceiro e quarto ciclos: Educação Física / Secretaria de Ensino Fundamental. Brasília: MEC/SEF, 1998.

BRASIL. Lei $\mathrm{n}^{\mathbf{0}}$ 10.639, de 09 de janeiro de 2003. Disponível em: <http://www.planalto.gov.br/ccivil_03/leis/2003/L10.639.htm>. Acesso em: 14 ago. 2015.

BRASIL. Lei $\mathrm{n}^{\mathrm{o}}$ 10.678, de 23 de maio de 2003. Disponível em: <http://www.planalto.gov.br/ccivil_03/leis/2003/L10.678.htm>. Acesso em: 14 ago. 2015.

BRASIL. Ministério da Educação. Diretrizes curriculares nacionais para a educação das relações étnico-raciais e para o ensino de história e cultura afro-brasileira e africana. Brasília: MEC/SECAD/SEPPIR/INEP, 2004. Disponível em: <http://webcache.googleusercontent.com/search?q=cache:hjqDXayNqN4J:www.acaoeducativa. org.br/fdh/wp-content/uploads/2012/10/DCN-s-Educacao-das-Relacoes-Etnico-

Raciais.pdf $+\& c d=1 \& h l=p t-B R \& c t=c \ln k \& g l=b r>$. Acesso em: 18 jul. 2015.

BRASIL. Ministério da educação. Notícias: Lei obriga ensino de história e cultura afro. Sextafeira, 09 de novembro de 2007. Disponível em: $<$ http://portal.mec.gov.br/component/content/article?id=9403:sp-482745990>. Acesso em: 19 jul. 2015.

BRASIL. Lei $\mathbf{n}^{\mathbf{0}}$ 11.645, de 10 de março de 2008. Disponível em: <http://www.planalto.gov.br/ccivil_03/_ato2007-2010/2008/lei/111645.htm>. Acesso em: 14 ago. 2015. 
BRASIL. Ministério da Educação. Plano Nacional das Diretrizes Curriculares Nacionais para a Educação das Relações Étnico-raciais e para o Ensino de História e Cultura Afrobrasileira e Africana. Brasília: SECAD; SEPPIR, 2009. Disponível em: $<$ http:/ portal.mec.gov.br/index.php?option $=$ com_docman\&view $=$ download\&alias $=10098$ diretrizes-curriculares\&category_slug=fevereiro-2012-pdf\&Itemid=30192>. Acesso em: 21 out. 2016.

BRASIL. Lei $\mathrm{n}^{\mathbf{0}}$ 12.288, de 20 de julho de 2010. Disponível em: <http://www.planalto.gov.br/ccivil_03/_Ato2007-2010/2010/Lei/L12288.htm>. Acesso em: 14 ago. 2015.

BRASIL. Lei $\mathbf{n}^{\circ}$ 12.711, de 29 de agosto de 2012. Disponível em: <http://www.planalto.gov.br/ccivil_03/_ato2011-2014/2012/lei/112711.htm>. Acesso em: 14 ago. 2015.

BRASIL. Lei $\mathrm{n}^{\mathrm{o}}$ 12.990, de 09 de junho de 2014. Disponível em: <http://www.planalto.gov.br/ccivil_03/_Ato2011-2014/2014/Lei/L12990.htm>. Acesso em: 14 ago. 2015.

CORREAA, I. L. de S. Cultura corporal afro-brasileira na escola: resistência e perspectiva de estudantes do ensino médio. Cadernos de Aplicação, Porto Alegre, v. 25, n. 1, p. 81-105, 2012.

CRUZ, G. de C.; EL TASSA, K. O. M. A inclusão escolar na formação de professores: perspectivas da Educação Física. In: Congresso Ibero Americano de Política e Administração da Educação, 3., 2012, Zaragoza, Espanha. Anais... Zaragoza, Espanha: CSMA, 2012. p. 1-14.

DARIDO, S. C. Diferentes concepções sobre o papel da Educação Física na escola. Cadernos de Formação: Conteúdos e Didática de Educação Física, São Paulo, v. 16, p. 34-50, 2012.

DARIDO, S. C. Educação Física na escola: questões e reflexões. Rio de Janeiro: Guanabara Koogan, 2003.

DARIDO, S. C. et al. A Educação Física, a formação do cidadão e os parâmetros curriculares nacionais. Revista Paulista de Educação Física, São Carlos, v. 15, n. 1, p. 17-32, 2001.

DOMINGUES, P. Movimento Negro Brasileiro: alguns apontamentos históricos. Revista Tempo, Rio de Janeiro, v. 12, n. 23, p. 100-122, 2007. DOI: 10.1590/S1413-77042007000200007

FERNANDES, F. A integração do negro na sociedade de classes. São Paulo: Dominus, 1965.

FREIRE, S. Um olhar sobre a inclusão. Revista Educação, Lisboa, v. 16, n. 1, p. 5-20, 2008.

GÓIS JÚNIOR, E.; LOVISOLO H. R. A Educação Física e concepções higienistas sobre raça: uma reinterpretação histórica da Educação Física brasileira dos anos de 1930. Revista Portuguesa de Ciências do Desporto, Porto, v. 5, n. 3, p. 322-328, set. 2005.

GOMES, N. L. Educação, relações étnico-raciais e a Lei 10.639/2003. A Cor da Cultura, 2011. Disponível em: <http://antigo.acordacultura.org.br/artigo-25-08-2011>. Acesso em: 17 jul. 2015. 
GONÇALVES, M. A. S. A Educação Física e a questão da discriminação racial. Revista Kinesis, Santa Maria, v. 8, p. 77-88, jul./dez. 1991. DOI: 10.5902/23165464843

GUIMARÃES, A. A. et al. Educação Física Escolar: atitudes e valores. Motriz, Rio Claro, v. 7, n. 1, p. 17-22, jan./jun. 2001.

HASENBALG, C. Discriminação e desigualdades raciais no Brasil. Rio de Janeiro: Graal, 1979.

HENRIQUES, R. Desigualdade racial no Brasil: evolução das condições de vida na década de 90. Rio de Janeiro: IPEA, 2001.

HERINGER, R. Desigualdades raciais no Brasil: síntese de indicadores e desafios no campo das políticas públicas. Cadernos de Saúde Pública, Rio de Janeiro, v. 18, p. 57-65, 2002. DOI: 10.1590/S0102-311X2002000700007

INSTITUTO DE PESQUISA ECONÔMICA APLICADA. Retrato das desigualdades de gênero e raça. Brasília: IPEA, 2011.

LEAL, G. F. A noção de exclusão social em debate: aplicabilidade e implicações para a intervenção prática. In: Encontro Nacional de Estudos Populacionais, ABEP, 15., 2004, Caxambu-MG. Anais... Caxambu-MG: UFMG, 2004. p. 1-17.

LIMA, M. Desigualdades raciais e políticas públicas: ações afirmativas no governo Lula. Novos Estudos - CEBRAP, São Paulo, n. 87, p. 77-85, jul. 2010. DOI: 10.1590/S010133002010000200005

MUNANGA, K. Por que ensinar a história da África e do negro no Brasil de hoje? Revista do Instituto de Estudos Brasileiros, São Paulo, n. 62, p. 20-31, dez. 2015. DOI: 10.11606/issn.2316-901X.v0i62p20-31

NABUCO, J. O abolicionismo. Petrópolis: Vozes, 1988.

PAIXÃO, M. Desigualdade nas questões racial e social. In: BRANDÃO, A. P. (Coord.). A Cor da Cultura - Saberes e Fazeres - Modos de Ver. Rio de Janeiro: Fundação Roberto Marinho, 2006. em: <http://www.acordacultura.org.br/sites/default/files/kit/Caderno1_ModosDeVer.pdf>. Acesso em: 20 out. 2016.

RODRIGUES, V. E. et al. A pobreza e a exclusão social: teorias, conceitos e políticas sociais em Portugal. Revista da Faculdade de Letras: Sociologia, Porto, v. 9, p. 63-101, 1999.

SALES, L. V.; ALMEIDA, N. F. P. Diversidade racial e Educação Física escolar na revista brasileira de ciências do esporte (1979-2013). Conexões, Campinas, v. 13, n. 1, p. 129-161, 2015. DOI: $10.20396 /$ conex.v13i1.2153

SCHWARCZ, L. M. O Espetáculo das Raças: cientistas, instituições e questão racial no Brasil, 1870-1930. São Paulo: Companhia das Letras, 1993. 
SCHWARTZMAN, S. Pobreza, exclusão social e modernidade: uma introdução ao mundo contemporâneo. São Paulo: Augurium, 2004.

SILVA, M. C. de P.; MOREIRA, A. de J. A cultura corporal nas diretrizes da Lei no 10.639/2003 da Secretaria Municipal de Educação e Cultura de Salvador: propósitos e despropósitos. In: TENÓRIO, R.; LORDÊLO, J. A. C. (Org.). Educação básica: contribuições da pós-graduação e da pesquisa. Salvador: EDUFBA, 2009.

SILVÉRIO, V. R. Ação afirmativa e o combate ao racismo institucional no Brasil. Cadernos de Pesquisa, São Paulo, n. 117, p. 219-246, nov. 2002. DOI: 10.1590/S0100-15742002000300012

SOARES, C. L. et al. Metodologia do Ensino de Educação Física. São Paulo: Cortez, 1992.

THEODORO, M. A formação do mercado de trabalho e a questão racial no Brasil. In: THEODORO, M. (Org); JACCOUD, L.; OSÓRIO, R.; SOARES, S. As políticas públicas e a desigualdade racial no Brasil - 120 anos após a abolição. Brasília: IPEA, 2008. p. 15-44.

THEODORO, M. (Org); JACCOUD, L.; OSÓRIO, R.; SOARES, S. As políticas públicas e a desigualdade racial no Brasil - 120 anos após a abolição. Brasília: IPEA, 2008. Disponível em: $<$ http://www.novamerica.org.br/medh2/arquivos/Livro_desigualdadesraciais.pdf $>$. Acesso em: 20 out. 2016.

VAGO, T. M. Cultura escolar, cultivo de corpos: educação physica e gymnastica como práticas constitutivas dos corpos de crianças no ensino público primário de Belo Horizonte (1906-1920). Educar em Revista, Curitiba, n. 16, p. 121-135, jan./dez. 2000. DOI: 10.1590/0104-4060.210

Recebido em 31/05/2016

Versão corrigida recebida em 25/10/2016

Aceito em 01/11/2016

Práxis Educativa, Ponta Grossa, v. 12, n. 2, p. 520-535, maio/ago. 2017 Disponível em: <http://www.revistas2.uepg.br/index.php/praxiseducativa > 